\title{
Acoustic Noise Reduction and Power Factor Correction in Switched Reluctance Motor Drives
}

\author{
Amir Rashidi ${ }^{\dagger}$, Sayed Mortaza Saghaiannejad*, and Sayed Javad Mousavi* \\ $\dagger *$ Dept. of Electrical and Computer Eng., Isfahan University of Technology, Isfahan, Iran
}

\begin{abstract}
In this paper, a four-phase 8/6-pole 4-kW SR motor drive model is presented. Based on experimental data, the model allows an accurate simulation of a drive in dynamic operation. Simulations are performed and a laboratory type set-up is built based on a TI TMS320F2812 platform to experimentally verify the theoretical results obtained for a SR motor. To reduce acoustic noise and to correct the power factor of this drive, a two-stage power converter is proposed that uses a current source rectifier (CSR) as the input stage for the asymmetrical converter of the studied SRM. Employing the space-vector modulation (SVM) method in matrix converters, the CSR switching allows the dc link's capacitors to be eliminated and the power factor of the SRM drive to be improved. As the electrical motive force (emf) is directly proportional to the rotor speed, the input voltage to the machine can be programmed to be a function of the speed with the modulation index of the CSR, leading to a reduction in the acoustic noise of the SRM drive. Simulation of the whole SRM drive system is performed using MATLAB-Simulink. The results fully comply with the required conditions such as power factor correction with an improvement in the THD.
\end{abstract}

Key Words: Acoustic Noise, Power Factor, Space Vector Modulation (SVM), Switched Reluctance Motor (SRM)

\section{INTRODUCTION}

Switched reluctance motors have been used since 1969 for variable speed applications due to the advent of inexpensive, high power switching devices. They have the wound field coils of a dc motor for their stator windings while the rotors have no windings or magnets. Being brushless, SRM drives enjoy such unique features as concentric windings, low resistance, low moment of inertia, comparable power density, negligible mutual coupling, higher or comparable reliability, and low cost, which make them ideal for many industrial applications. However, they suffer from a poor operating power factor, which results in increased losses in power distribution systems. Therefore, improving the power factor is beneficial to enhancing their commercial competitiveness. Moreover, vibrations and the resulting acoustic noise are mentioned as drawbacks of SRM machines [1].

New applications for variable speed drives are cost sensitive while highly reliable, equally performing dc and induction motor drives at the minimum are also demanded. SRM drives are promising systems to meet these demands in some select high-volume applications; hence, the spurt of activity in this field [2], [3].

A conventional converter for a SR drive uses a diode bridge rectifier and a large filter capacitor on the front-end. Since the diode rectifier draws a pulse current from the ac source side,

Manuscript received Jan. 20, 2010; revised Oct. 20, 2010

$\dagger$ Corresponding Author: 315.amir@gmail.com

Tel: +98-311-391-5481, Fax: +98-311-391-2451, Isfahan Univ. of Tech

* Dept. of Electrical and Computer Eng., Isfahan University of Technology, Iran the system is associated with a low power factor $(\mathrm{PF})$ and low system efficiency. Therefore, SR drive systems always have the disadvantages of a low PF and a high current and harmonics. On the other hand, due to its double saliency structure and concentrated magnetic flux, a SR motor is prone to higher levels of acoustic noise. The noise and vibrations are specifically higher in low-speed operating regimes when the motor is typically controlled by a chopping-controlled mode.

In order to improve the power factor of a SR motor and also to reduce its acoustic noise, a two-stage power converter is proposed in this paper. The subsystem models and their derivation as well as a procedure for simulating a four-phase 8/6-pole 4-kW SR motor drive using Matlab/Simulink are also introduced. The four quadrant drive system dynamic performances will be illustrated and experimental results will be presented. Finally, the validity of the proposed two-stage power converter will be analyzed by mathematical modeling and tested by simulations.

\section{SRM OPERATING PRINCIPLE}

Fig. 1 shows a 6/4-pole (six stator poles and four rotor poles), three-phase, doubly salient reluctance machine and the semiconductor switches controlling a single phase of the machine. The rotor poles have just passed their unaligned position with respect to the stator phase $\mathrm{A}$ and the poles (a) will be in the aligned position with the stator poles AA when the rotor moves counterclockwise towards the excited phase A-A. The operating principle of a switched reluctance machine is based on the power effects of the magnetic circuit that tend to minimize the reluctance of the magnetic circuit. If 


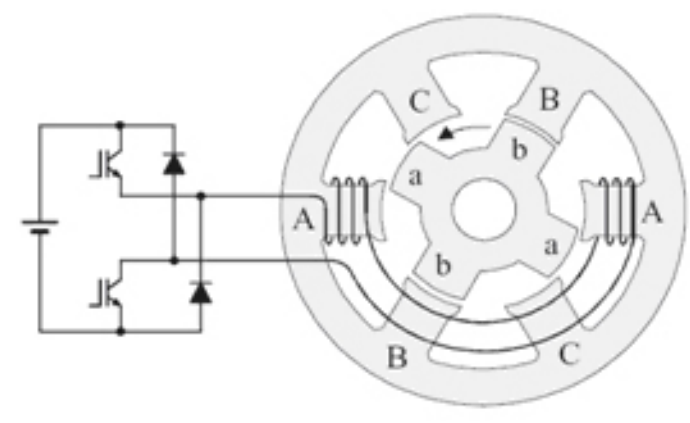

Fig. 1. A 6/4 SRM with conventional converter for one phase.

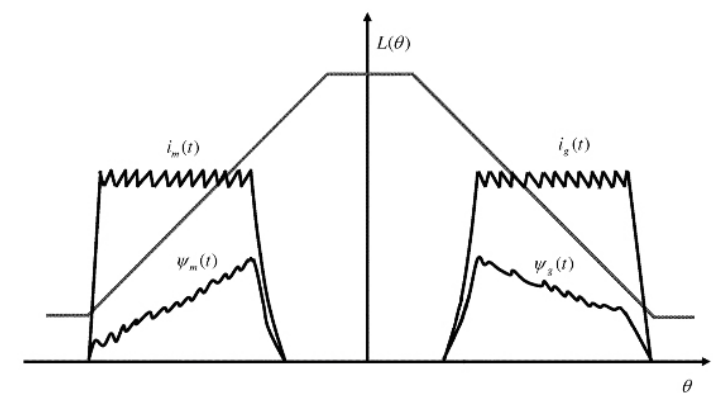

Fig. 2. Inductance profile as well as the motoring and regenerative actions of the SRM.

the current is led to phase A of the machine, the rotor tries to turn counterclockwise so that the reluctance of the magnetic circuit of phase A will reach its minimum and the energy of the magnetic circuit will, thus, be minimized. When the energy minimum of phase B has been reached, the magnetic forces try to keep the rotor in a position in which the energy minimum of the magnetic circuit is preserved. In this situation, the magnetic energy has to be removed from phase B to make the machine rotate again. Accordingly, the current supply is started in phase $\mathrm{A}$ at an instant when the poles of the rotor and the stator are about to overlap. By connecting the currents to different phases at the correct instants and with suitable magnitudes, a high, almost smooth sum torque can be reached over a wide range of rotation speeds. Moreover, it is easier to load the rotor at zero speed in this system than it is in traditional electrical machines.

The expression for the electromagnetic torque of the SRM is a function of the phase current and position as follows:

$$
T_{e}=\frac{d L(\theta, i)}{d \theta} \cdot \frac{i^{2}}{2}
$$

By appropriately positioning the phase currents relevant to the rotor position, four-quadrant operation is obtained. To generate a motoring torque, the phase current is switched on during the rising slope portion of the phase inductance as shown in Fig. 2. If the phase current is applied on the falling slope portion of the phase inductance, a regenerating torque is produced [2].

\section{Modeling OF THE SRM DRIVE SySTEM}

Dynamic modeling, simulation, and analysis play crucial roles in drive system analysis. Simulation of the drive system

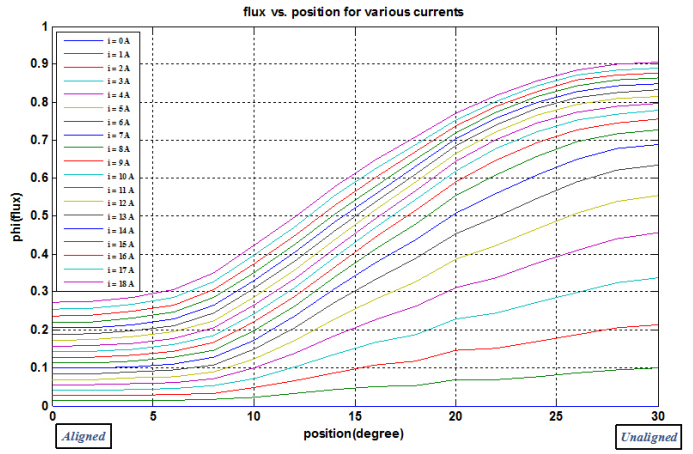

Fig. 3. Flux linkages vs. current vs. rotor position characteristics of an $8 / 6$ SRM.

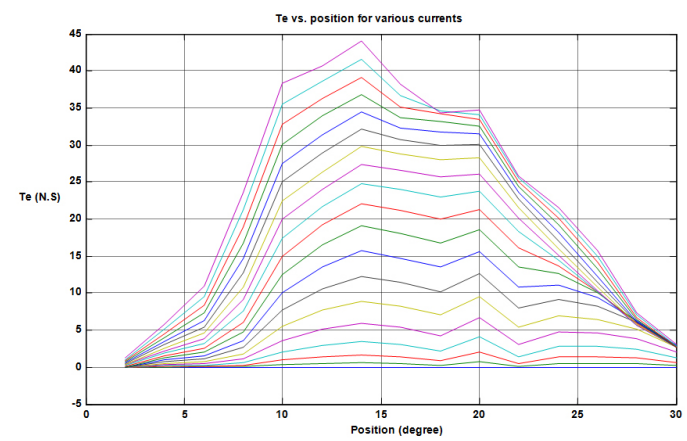

Fig. 4. Torque vs. rotor position vs. current characteristics of an 8/6 SRM.

requires models for the SRM drive subsystems and their interconnections. This section contains the subsystem models, their derivation and a procedure for simulating the drive system.

\section{A. Magnetization characteristics}

The magnetization characteristics of a machine can be obtained by a finite element simulation of the machine given the B-H characteristics of the lamination material, the machine dimensions, and the winding data. Alternatively, they can be either measured or computed by an analytical approach using finite element analysis methods. The magnetization characteristics of this machine are obtained in [4]. These characteristics (flux linkages vs. current vs. rotor position and air gap torque vs. current vs. rotor position, respectively) are shown for a $4 \mathrm{kw}, 8 / 6$ switched reluctance motor in Fig. 3 and 4.

\section{B. Machine modeling}

The modeling of various subsystems of the SRM drive is considered in this section. The model of the machine is derived in terms of the three dimensional relationships of its flux linkages, current, and rotor positions and air gap torque, current, and rotor position.

In this model, currents are produced by the nonlinear function $I(\psi, \theta)$ which is implemented as a lookup Table. The electromagnetic torques produced by the stator phases are provided by the nonlinear function $T_{e}(i, \theta)$ also implemented as a lookup Table [5]. The torques produced by all of the stator phases are then summed up to provide the total torque on the rotor shaft. These data for the $4 \mathrm{kw}, 8 / 6$ switched 


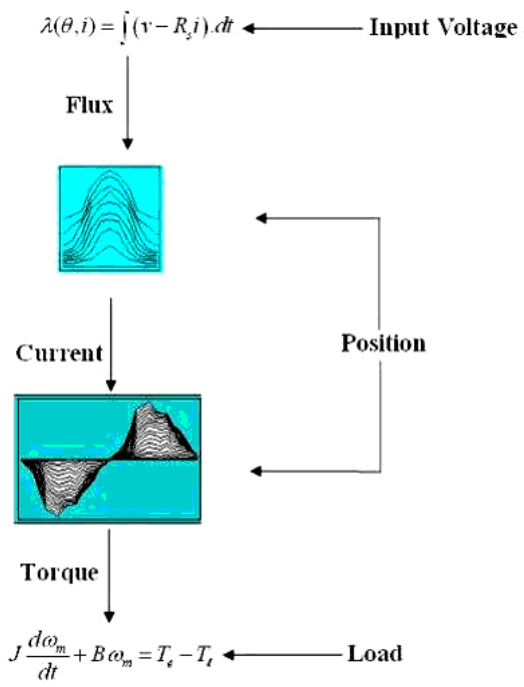

Fig. 5. SRM model configuration.

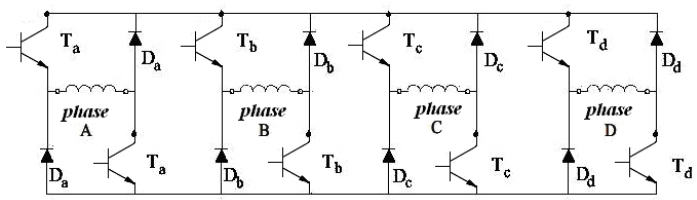

Fig. 6. Asymmetric converter for SRM.

reluctance motor for a finite set of currents and rotor positions are implemented in the lookup Tables of the model.

The load dynamic equation is:

$$
J \frac{d \omega_{m}}{d t}+B \omega_{m}=T_{e}-T_{\ell}
$$

where, $T_{e}$ is the electromagnetic torque obtained from the machine characteristics as a function of $i$ and $\theta, T_{l}$ is the load torque, $\omega_{m}$ is the rotor speed, $J$ is the rotor and load inertia, and $B$ is the friction coefficient of the motor and the load.

Fig. 5 shows a block diagram of a four-phase 8/6 SRM.

\section{Power converter model}

Fig. 6 shows a conventional asymmetric converter for a fourphase SR drive circuit. The drive circuit has a simple diode rectifier, a filter capacitor, and an asymmetric bridge converter. The rectifier and the filter capacitor supply the dc source. The filter capacitor reduces the dc voltage ripple and stores the recovered energy from the motor during demagnetization [6].

The model contains standard SimPowerSystem components for the power IGBTs and diodes. The SRM phase model based on the experimentally determined characteristics of the motor is linked to the power converter model with the current and voltage sources as standard library components. The model can be used to simulate four-quadrant operations of a switched reluctance motor drive.

\section{Acoustic NoIse}

If one dimension expands, then the other contracts to preserve the volume. As shown in Fig. 7, changing magnetization

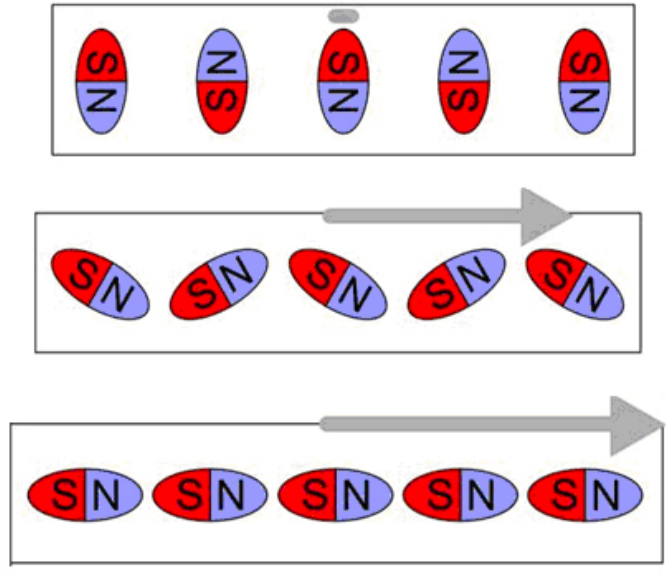

Fig. 7. Changing magnetization changes the physical dimensions of the material.

changes the physical dimensions of the material. The red-blue elements show the magnetic domains and the grey arrows show the direction and value of the external magnetic field.

The magnetic flux in the machine passes across the air gap in an approximately radial direction producing radial forces on the stator and the rotor, which results in magnetic noise and vibrations. This is the most dominant source of noise generation in a SRM as well as in other electrical machines. The stator vibration is found to be proportional to the rate of demagnetization. During commutation, when the phase winding is demagnetized, the stator vibrates, and this vibration produces a high acoustic noise. The radial force is expressed by:

$$
F_{r}=-\frac{r L \theta}{2 \mu_{\circ}} B_{g}^{2}\left(\theta, l_{g}, i\right)
$$

where, $B_{g}$ is the air gap flux density, $\theta$ is the rotor position, $l_{g}$ is the minimum airgap between the stator and the rotor at the aligned position, $L$ is the selfinductance of the winding, and $i$ is the winding current [1].

As the induced emf is directly proportional to rotor speed, the input voltage to the machine can be programmed to be a function of the speed. At speeds lower than the rated speed, the rate of change in the current is reduced as the available input voltage is made lower than the source voltage. When a particular phase is energized, the corresponding stator pole is pulled inward due to a strong radial attraction between the stator and rotor poles. As a result, the stator assumes an oval shape. In this condition, if the phase winding is demagnetized instantaneously by applying a high negative voltage across it, a severe stator vibration will take place, which will produce an audible noise. Thus, the amplitude of the noise and the vibration will be proportional to the rate of the demagnetization of the winding - the faster it is demagnetized, the more audible the noise will be. Hence, slow demagnetization of the phase winding can be thought of as a remedy to such vibration and acoustic noise in SR motors. In this paper, a variable input voltage controller is proposed to reduce the rate of demagnetization [7]. 


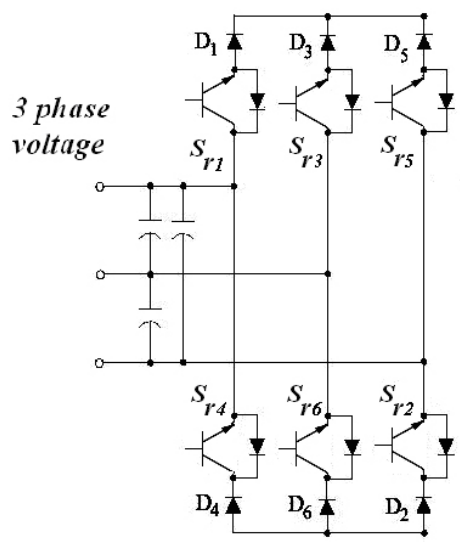

Fig. 8. Current source rectifier.

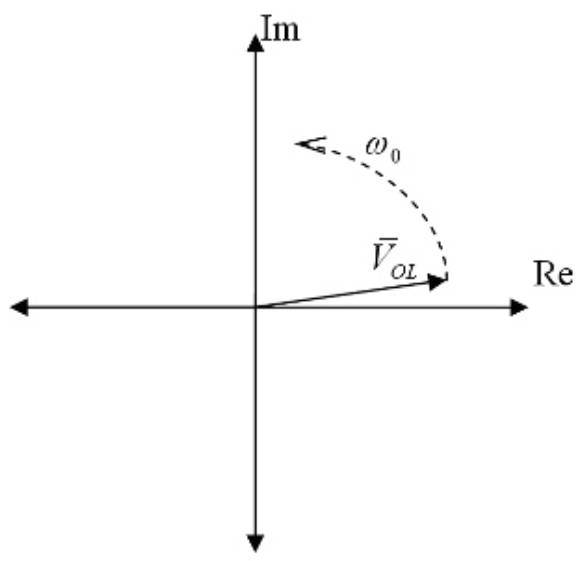

Fig. 9. Output line-voltage space vector.

\section{The Proposed Two-Stage Power Converter}

A two-stage power converter is proposed here to improve the power factor of the drive. The first stage (Fig. 8) consists of a controllable converter with six switches and six diodes. This stage is a controlled rectifier but without the drawbacks of a low power factor and high input line harmonics. Using a CSR in the SRM converter input results in eliminating the dc link's capacitors, which keeps the expense of implementing this model unchanged but enhances the reliability of the scheme and increases its power density. The other power stage is an asymmetrical converter.

The resulting output line-voltage space vector is defined by:

$$
\bar{V}_{O L}=v_{A B}(t)+\bar{a} \cdot v_{B C}(t)+\bar{a}^{2} \cdot v_{C A}(t)
$$

where, $\bar{a}$ is a phasor with unit amplitude and an angle of $120^{\circ}$. This vector is shown in Fig. 9.

The SVM technique applied to the CSR is based on the representation of the required instantaneous input current vector in the complex plane according to the voltage vector. Thus, a unit power factor will be achieved. The CSR switching states can be observed in Table I. As can be seen, two switches of this structure are on for every switching state. Due to topological restrictions, the CSR may assume only nine switching combinations, i.e. a path must be provided for the output inductor current and a short circuit must not be applied
TABLE I

CSR SWITCHING STATES

\begin{tabular}{|c|c|}
\hline Switching state vectors & On switches \\
\hline$I_{1}(a, c)$ & $T_{1}, T_{2}$ \\
\hline$I_{2}(a, c)$ & $T_{2}, T_{3}$ \\
\hline$I_{3}(a, c)$ & $T_{3}, T_{4}$ \\
\hline$I_{4}(a, c)$ & $T_{4}, T_{5}$ \\
\hline$I_{5}(a, c)$ & $T_{5}, T_{6}$ \\
\hline$I_{6}(a, c)$ & $T_{1}, T_{6}$ \\
\hline$I_{0}(a, c)$ & $T_{1}, T_{4}$ \\
\hline$I_{0}(a, c)$ & $T_{3}, T_{6}$ \\
\hline$I_{0}(a, c)$ & $T_{2}, T_{5}$ \\
\hline
\end{tabular}

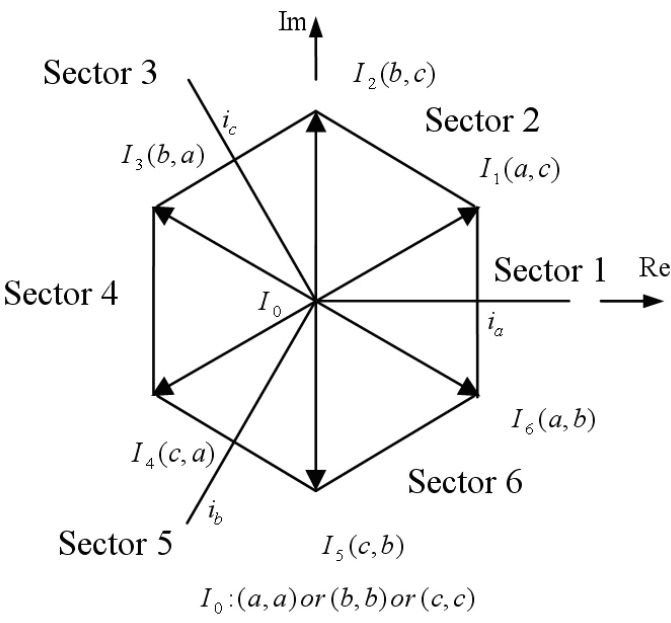

Fig. 10. CSR space vectors and sector definitions.

to the main filtering capacitors. In other words, only one of the three switches at the top and at the bottom of the bridge must be $\mathrm{ON}$ at any given time [8],[9]. The reference current vector can be realized by using the two limiting active vectors of the sector as shown in Fig. 10.

Using the law of sines, the duty cycles of the switching state vectors are:

$$
\begin{aligned}
d_{\mu} & =T_{\mu} / T_{S}=m_{c} \cdot \sin \left(60^{\circ}-\theta_{s c}\right), \\
d_{v} & =T_{v} / T_{S}=m_{c} \cdot \sin \left(\theta_{s c}\right), \\
d_{0 c} & =T_{0 c} / T_{S}=1-d_{\mu}-d_{v}
\end{aligned}
$$

where, $\mathrm{mc}$ is the modulation index, $T_{S}$ is the sampling interval and $\theta_{s c}$ is the angle between the reference vector and the first active vector.

\section{System Block Diagram}

By combining the various blocks of the described drive system, system equations are assembled which contain differential, algebraic, and conditional equations. The general schematic of the drive system is shown in Fig. 11.

\section{EXPERIMENTAL AND SimUlation RESULTS}

This section presents the simulation and experimental results of the SRM drive system. Figure 12 shows the speed, current, flux, and torque of the machine vs. time.

In this paper, the current control is achieved by a closedloop control with hysteresis switching control of the converter. 


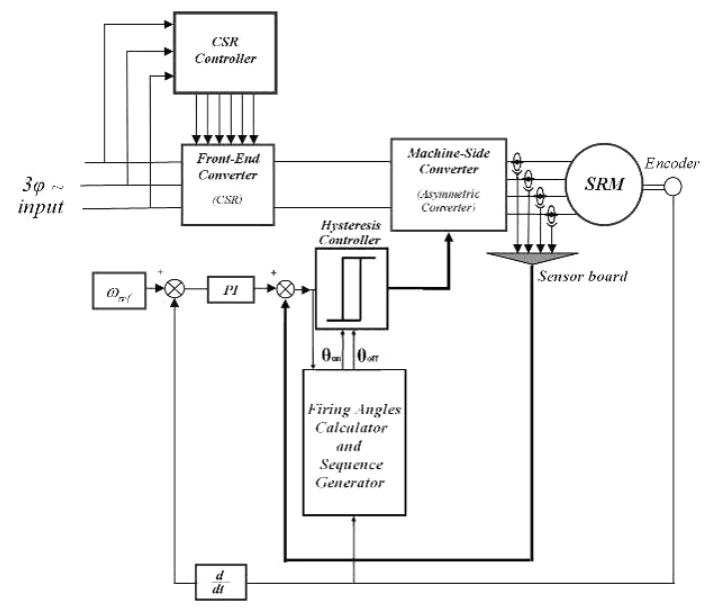

Fig. 11. The proposed closed-loop SRM drive system.

TABLE II

MOTOR SPECIFICATIONS

\begin{tabular}{|l|l|}
\hline Rated power & $4 \mathrm{~kW}$ \\
Rated phase current & $9 \mathrm{~A}$ \\
Rated speed & $1500 \mathrm{rpm}$ \\
Number of pole & $8 / 6$ \\
Phase resistance & $0.75 \Omega$ \\
\hline
\end{tabular}

The shape of the energy-conversion loop is an important guide to the effectiveness of basic control strategies. It is often the main objective of an average torque control to maximize its area for a given peak or r.m.s, current. Dynamic simulation results are obtained for the prototype 4 phase 8/6 SRM. The energy conversion loops are presented in Fig. 13. At high speeds, the motor's EMF increases and the available voltage may be insufficient for chopping, so that the torque can be controlled only by varying the firing angles of a single pulse of the current [1].

In the experimental set-up, a dc machine is mechanically coupled to the SRM. The SRM rotor position is obtained from an optical encoder which is installed on the rotor shaft. The SRM drive system is conducted on a partial load. The current reference is $3(\mathrm{~A})$. The drive is operated at $1 / 4^{\text {rd }}$ base speed. The parameters of the $8 / 6$ pole SR motor used for testing and analysis are presented in Table II.

All of the experimental hardware used for evaluating the $8 / 6$ SRM drive is shown in Fig. 14. The main power converter and the chopper are mounted on a workbench, as shown in the picture. A fixed point, TI DSP is used for executing the control algorithm.

Fig. 15 show a typical current and voltage phase of the SR motor obtained for a constant conduction angle.

This drive structure is very simple, but the capacitor charges and discharges as shown in Fig. 16, which illustrates a pulsating ac line current, and results in a low PF. The low $\mathrm{PF}$ of the motor increases the reactive power of the power line and decreases efficiency.

CSR simulations were performed using both the existing two-dimensional look-up Tables and a separate code written as an interface with SIMULINK. Fig. 17 shows the output voltage waveform of the CSR. In Fig. 18, the current of the R-L load of the CSR is controlled by a modulation index. Fig.

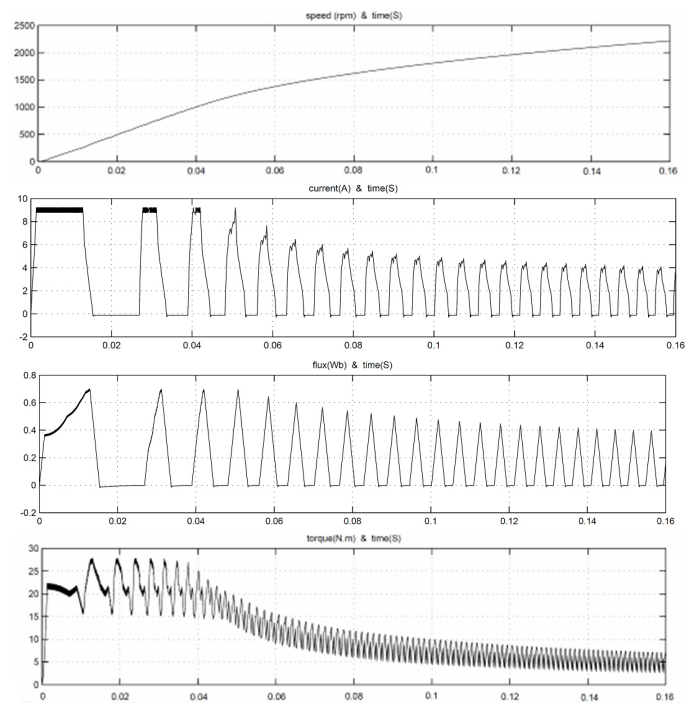

Fig. 12. Speed, current, flux, and torque of the $8 / 6$ SRM vs. time (up to down).

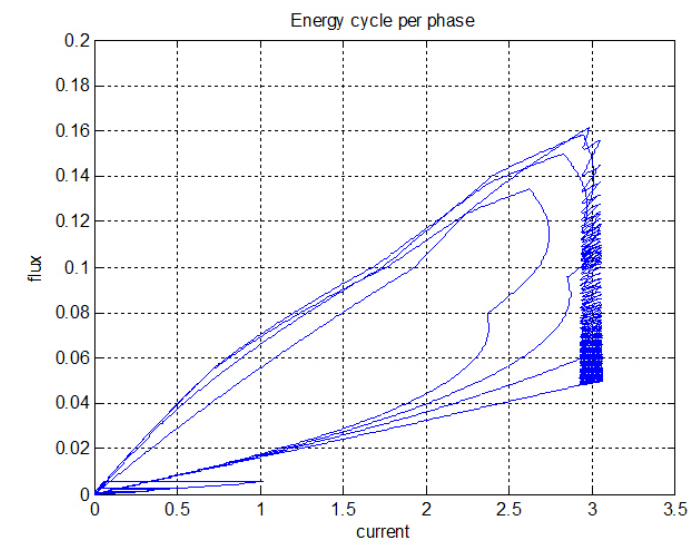

Fig. 13. Energy conversion loops for the 8/6 SR motor.

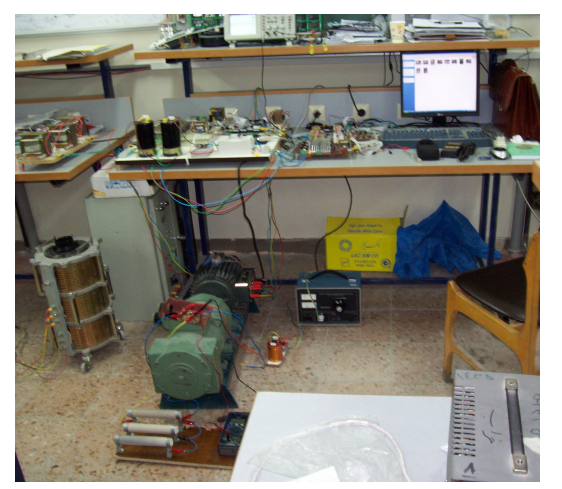

Fig. 14. Experimental SRM test setup used for experimentation. 

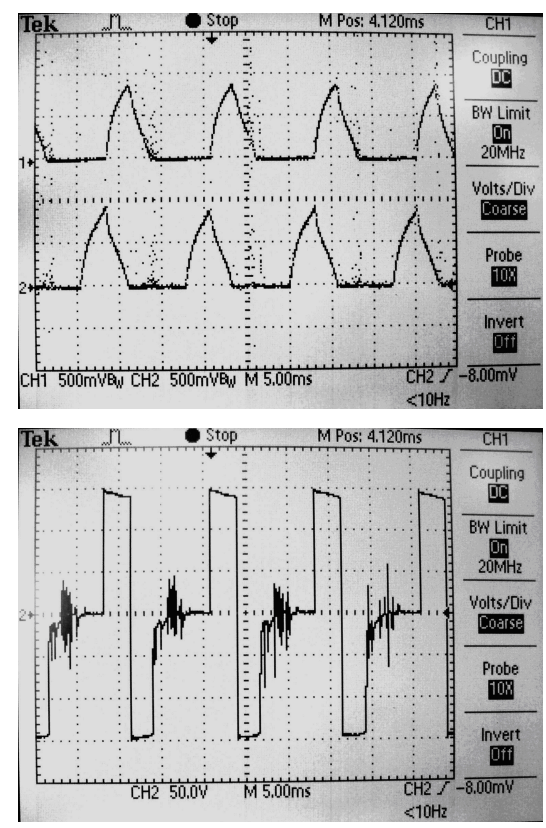

Fig. 15. Phase current (scale: phase current $=1.5 \mathrm{~A} / \mathrm{div}$, up) and Phase voltage of SRM (scale: phase voltage $=50 \mathrm{~V} / \mathrm{div}$, down).

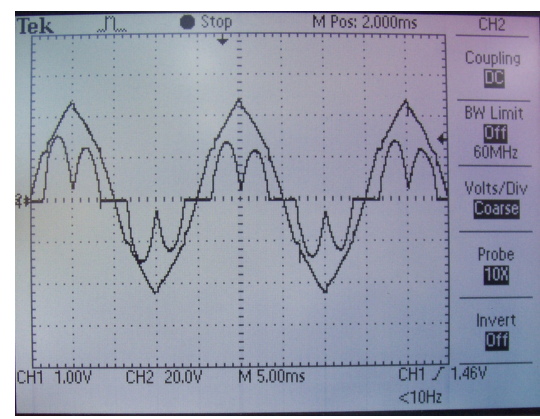

Fig. 16. Input voltage and input current of the SRM drive (scale: input voltage $=50 \mathrm{v} / \mathrm{div}$, input current $=1 \mathrm{~A} / \mathrm{div}$, and time $=5 \mathrm{~ms} / \mathrm{div})$.

19 shows the input voltage and current.

The output voltage waveform of the CSR clearly shows six order harmonics riding over a dc voltage with switching signals in the SVM mode.

By regulating the input voltage as a function of the speed (Fig. 20), the rate of the change of the demagnetization will be slow for all operating speeds and the vibration modes, which normally arise during demagnetization, will be damped out.

Fig. 21 shows the response of the system to a Trapezoidal reference speed profile, which is modified at $1 / 4^{\text {rd }}$ base speed.

Fig. 22 and 23 illustrate the line current of the SRM drive. The current spectra obtained with common and two-stage converters are presented in Fig. 24. As can be seen, the harmonic content is lower in the proposed topology than it is in the standard one. The power factor values are given in Table III. In the proposed converter, the power factor is higher than it is in the standard topology.

\section{CONCLUSIONS}

In this paper, a four-phase 8/6-pole 4-kW SR motor drive system is modeled and simulated based on experimental characteristics. A DSP-based 8/6 SRM equipped with an asym-

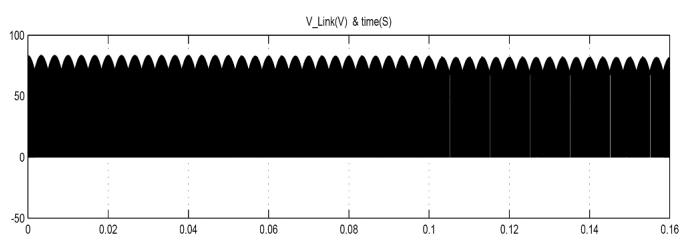

Fig. 17. Output voltage of CSR.

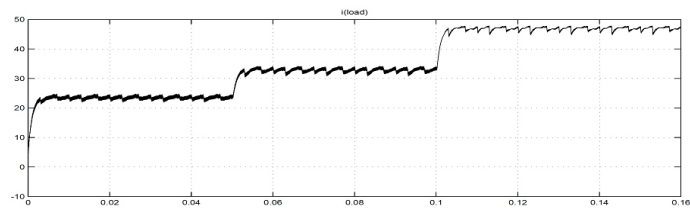

Fig. 18. R-L Load Current.
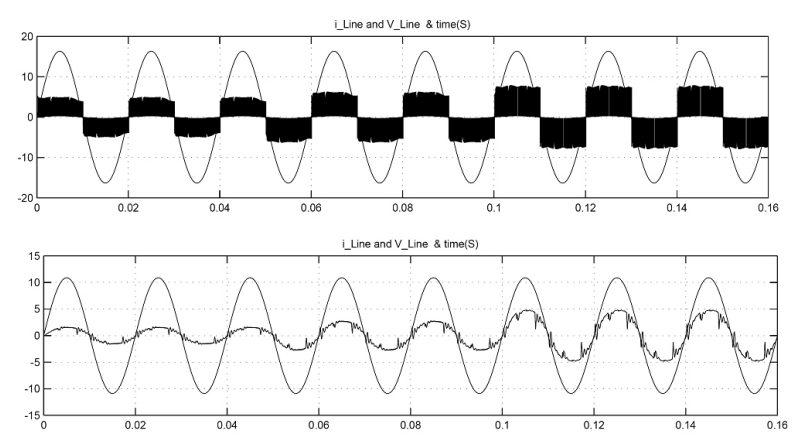

Fig. 19. Input line current and voltage without $1 \mu \mathrm{F}$ low-pass filter on the supply side(up), Input line current and voltage with $1 \mu \mathrm{F}$ low-pass filter(down).

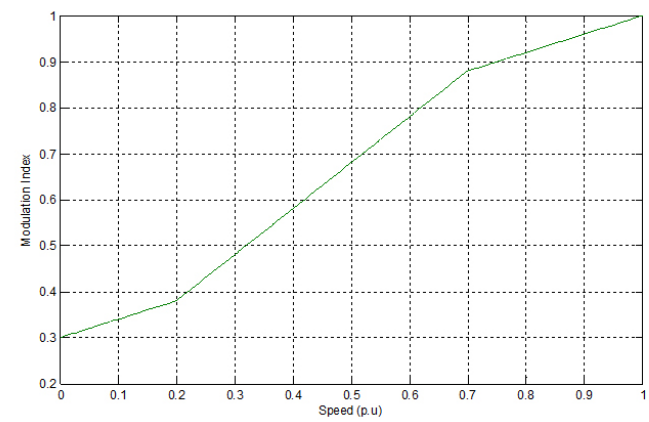

Fig. 20. CSR Modulation index versus speed (p.u) of the SRM.

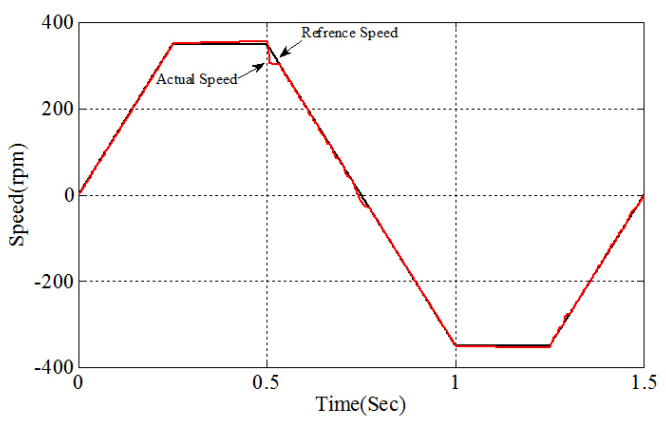

Fig. 21. Four quadrant speed response of SRM with CSR. 


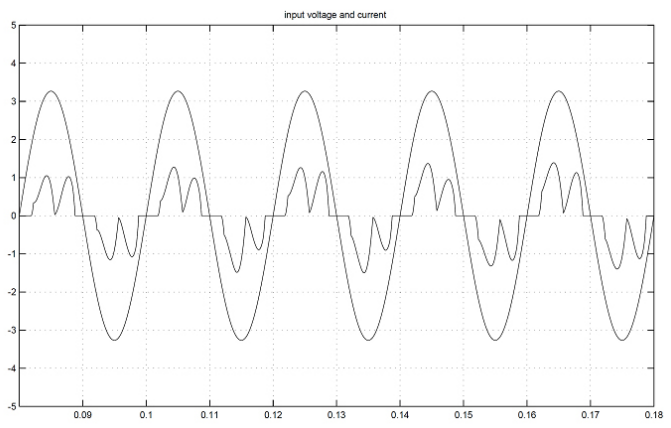

Fig. 22. Input voltage and current of SRM drive without CSR.

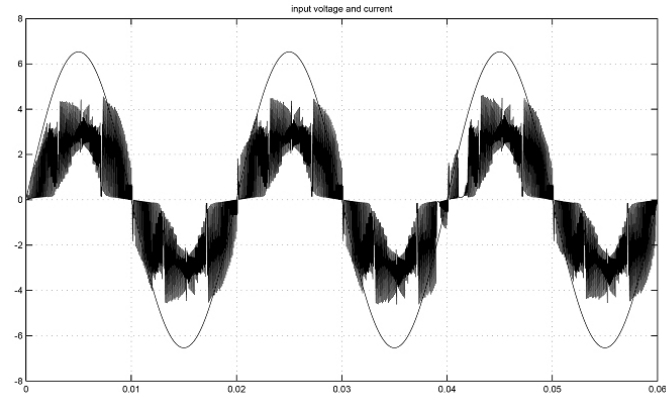

Fig. 23. Input voltage and current of SRM drive with CSR.
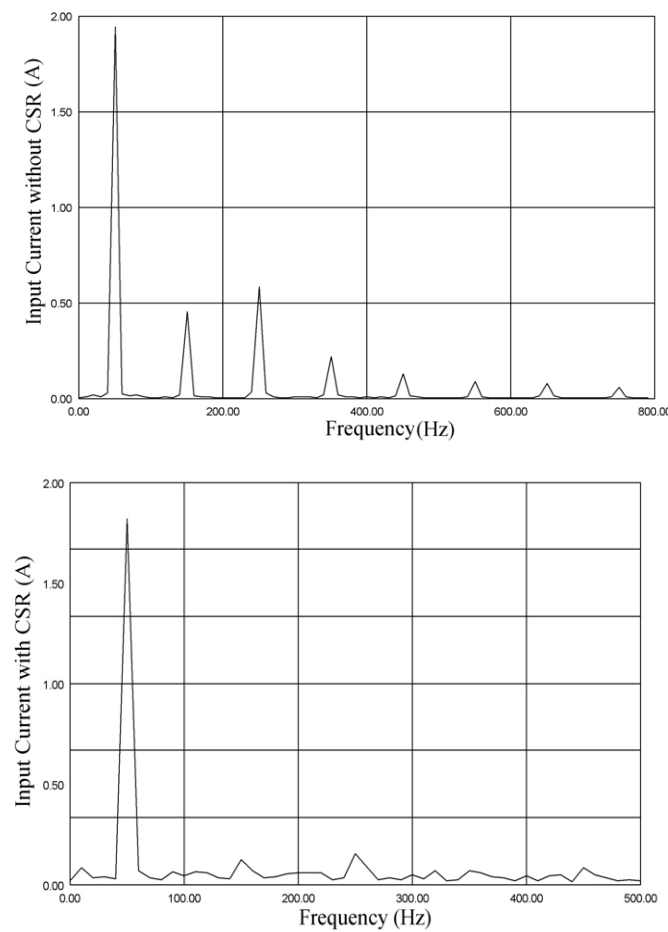

Fig. 24. Spectra of the input line current of the SRM drive without CSR (up) and with CSR (down).

TABLE III

POWER FACTOR EVALUATION

\begin{tabular}{|c|c|c|}
\hline \multirow{2}{*}{ Power } & \multicolumn{2}{|c|}{ Power Factor } \\
\cline { 2 - 3 } & SRM Drive & With CSR \\
\hline $100 \mathrm{~W}$ & 0.4 & 0.83 \\
\hline $600 \mathrm{~W}$ & 0.55 & 0.86 \\
\hline
\end{tabular}

metrical power converter with a hysteresis current controller is established to evaluate the input current of the drive. A twostage power converter is also proposed that both improves the power factor and reduces the acoustic noise. The first stage involves a CSR and the SVM technique is applied to it. This is easy to implement on a DSP and it presents a low total harmonic distortion factor. Simulation of the whole SRM drive system is performed using MATLAB-Simulink and Mfile.

The frequency spectra of the input phase current for both cases shows that the proposed converter greatly improves the THD of the current through correcting the power factor while allowing for speed control via controlling the link voltage using the modulation index.

One of the drawbacks associated with this two-stage converter is that it requires a higher number of power devices. Additionally, the use of a CSR may deteriorate the dynamic response of the SRM with respect to the dc link capacitor.

\section{REFERENCES}

[1] R. Krishnan, Switched Reluctance Motor Drives, Boca Raton, FL: CRC Press, 2001.

[2] J. Pyrhönen, T. Jokinen, V. Hrabovcova'; translated by H. Niemelä, textitDesign of Rotating Electrical Machines, John Wiley \& Sons, 2008.

[3] D.H. Lee, Z.G. Lee, J. Liang, , J. Ahn, "Single-phase SRM drive with torque ripple reduction and power factor correction," IEEE Trans. on Industry Applications, Vol. 43, No. 6, pp. 1578-1587, Nov./Dec. 2007.

[4] V. Ramanarayanan, L. Venkatesha, D. Panda, "Flux-linkage characteristics of switched reluctance motor," Power Electronics, Drives and Energy Systems for Industrial Growth, Vol.1, pp. 281-285, Jan. 1996.

[5] V. Ramanarayanan, D. Panda, "Mutual coupling and Its effect on steadystate performance and position estimation of even and odd number phase switched reluctance motor drive," IEEE Trans. on Magnetics, Vol. 43, No. 8, pp. 3445-3456, Aug. 2007.

[6] H. Keunsoo, L. Cheewoo, K. Jaehyuck, R. Krishnan, O. Seok-Gyu, "Design and development of low-cost and high-efficiency variable-speed drive system with switched reluctance motor," IEEE Trans. on Industry Applications, Vol. 43, No. 3, pp. 703 - 713, May/Jun. 2007.

[7] D. Panda, V. Ramanarayanan, "Reduced acoustic noise variable DCbus-voltage-based sensorless switched reluctance motor drive for HVAC applications," IEEE Trans. on Industrial Electronics, Vol. 54, No. 4, pp. 2065- 2078, Aug. 2007.

[8] G. Rim, R. Krishnan, "Variable speed constant frequency power conversion with a switched reluctance machine," Applied Power Electronics Conference and Exposition - APEC 1994, Vol.1, pp. 63 - 71, Feb. 1994.

[9] L. Huber and D. Borojevic, "Space vector modulated three-phase to three-phase matrix converter with input power factor correction," IEEE Trans. on Industry Applications, Vol. 31, No. 6, pp. 1234-1246, Nov./Dec. 1995.

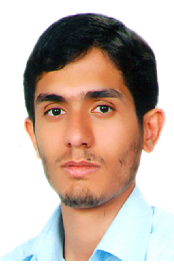

Amir Rashidi was born in Mashhad, Iran, in 1984. He received his B.S. from Sistan and Baluchestan University, Zahedan, Iran, in 2006 and his M.S. from Isfahan University of Technology, Isfahan, Iran, in 2009. His research interests include electric motor drives, power electronics and microprocessor-based control systems.

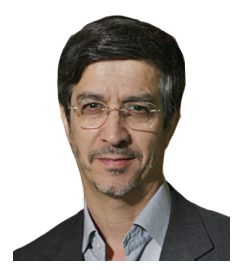

Sayed Mortaza Saghaiannejad was born in Isfahan, Iran, in 1952. He received his B.A., M.S. and Ph.D. in Electrical Engineering from the University of Kentucky, U.S.A. in 1977, 1979 and 1989, respectively. Since 1979, he has been with the Department of Electrical and Computer Engineering of Isfahan University of Technology, as a faculty member, where he is currently an Associate Professor. His research interests are in the areas of electrical machines, power electronics and 
Sayed Javad Mousavi was born in Tehran, Iran, in 1983. He received his B.S. from the Amirkabir University of Technology, Tafresh, Iran, in 2005 and his M.S. from Isfahan University of Technology, Isfahan, Iran, in 2008. His major research interests include matrix converters and power electronics. 